\title{
Coptis chinensis inhibits melanogenesis increasing miR-340-mediated suppression of microphathalmia-associated transcription factor
}

Hyun Kyung Lee ${ }^{1}$, Seonghee Jeong ${ }^{1}$, Shang Hun Shin ${ }^{1}$, Dahye Joo ${ }^{1}$, Seong Jin Choi ${ }^{1}$, Karam Kim ${ }^{1}$, In-Sook An ${ }^{1}$, Kyung-Yun Kim², Jung-Eun $\mathrm{Ku}^{3}$, Sun-Hee Jeong ${ }^{4}$ and Hwa Jun $\mathrm{Cha}^{5,6^{*}}$

\begin{abstract}
Background: Coptis chinensis (C. chinensis) contains various antioxidants, including berberine, epiberberlin, ferulic acid, magnoflorine, palmatine, and worenine, which have antibacterial, anti-inflammatory, haemostatic, hypotensive, and anticancer effects. In the present study, the melanogenesis-inhibiting effects of $\boldsymbol{C}$. chinensis were investigated and the molecular mechanisms were elucidated.

Methods: The melanogenesis-inhibiting effect of $C$. chinensis was verified by measuring melanin contents, melanogenesisrelated tyrosinase activities, and mRNA and protein expression levels of tyrosinase and microphthalmia-associated transcription factor (MITF). In addition, changes in miR-340 expression by C. chinensis were verified, and the activity of the miR-340 binding site of the target MITF gene was determined using luciferase reporter assays.

Results: Assays of melanin contents showed that C. chinensis had a skin-whitening effect and controlled mRNA and protein expression levels of tyrosinase. However, C. chinensis controlled protein levels of MITF without affecting mRNA levels. Determinations of miR-340 expression, which directly influences MITF translation, showed increased miR-340 mRNA levels in the presence of $C$. chinensis. Finally, luciferase reporter assays of the binding site on MITF showed that $C$. chinensis inhibits melanogenesis by directly controlling the miR-340-MITF axis.
\end{abstract}

Conclusions: The results of the present study verified the skin-whitening effect of $C$. chinensis and its molecular mechanisms and indicated that $C$. chinensis has high potential as an ingredient in skin-whitening cosmetics.

Keywords: Coptis chinensis, Tyrosinase, Melanogenesis, Melanin contents, MITF, miR-340, Skin-whitening effect

\section{Background}

Melanin is synthesized in melanosomes of melanocytes from basal layers of the epidermis and is transported to epidermal keratinocytes through dendrites to provide skin pigmentation and protection from ultraviolet light and external stimuli (Fajuyigbe and Young 2016; Fitzpatrick et al. 1967). However, excessive melanogenesis and abnormal melanin distribution may lead to the formation of melasmas and freckles

\footnotetext{
* Correspondence: hjcha@osan.ac.kr

${ }^{5}$ Department of Skin Care and Beauty, Osan University, Osan-si, Gyeonggi-do 18119, Republic of Korea

${ }^{6}$ Department of Skin Care and Cosmetics, Osan University, Osan-si45

Cheonghak-roGyeonggi-do 18119, Republic of Korea

Full list of author information is available at the end of the article
}

or may cause abnormal hyperpigmentation, such as spots during aging (Amaro-Ortiz et al. 2014). Melanogenesis is triggered by the conversion of tyrosine to dopaquinone by tyrosinase (Pillaiyar et al. 2017). Dopaquinone is then converted to dopachrome in the presence of thiol groups, and this metabolite is then converted by a tyrosinase-related protein (TRP)-2 into 5,6-dihydroxyindole-2-carboxylic acid, which is in turn converted by TRP-1 to indole-5,6-quinone-2-carboxylic acid to produce melanin (Tsukamoto et al. 1992; Boissy et al. 1998). The cyclic monophosphate/protein kinase A (cAMP/PKA) pathway is the main mode of signal transduction for melanin production, wherein cAMP, through PKA and cAMP-responsive element- 
binding protein 1 (CREB1), enhances the expression of microphthalmia-associated transcription factor (MITF) (D'Mello et al. 2016). MITF is a critical transcription factor for melanogenesis and is known to enhance the transcription of tyrosinase and its related proteins TRP-1 and TRP-2 (Buscà and Ballotti 2000; Saha et al. 2006). The cAMPderived $\alpha$-melanocyte-stimulating hormone $(\alpha-\mathrm{MSH})$ is a neuropeptide from proopiomelanocortin (POMC) that is produced in the hypophysis and in various other organs including the skin. In the skin, $\alpha-\mathrm{MSH}$ is produced by melanocytes, Langerhans cells, fibroblasts, and endotheliocytes and, particularly, in keratinocytes following exposure to ultraviolet light (Chakraborty et al. 1996). In addition, $\alpha-\mathrm{MSH}$ induces melanogenesis by increasing intracellular cAMP levels and membrane expression of the melanocortin-1 receptor (MC1R) (Videira et al. 2013). Therefore, modulation of intracellular signal transduction by $\alpha-\mathrm{MSH}$ is recognized as an important target for the control of melanogenesis (Nasti and Timares 2015). Multiple studies report effective skin-whitening effects of treatments that modulate MITF expression, and although the melanogenic gene tyrosinases, TRP-1 and TRP-2, have been implicated, control of tyrosinase activity and expression did not affect melanogenesis in isolation.

Coptis chinensis (C. chinensis) is a perennial plant of the Ranunculaceae family. C. chinensis produces the active ingredient of berberine, which is an isoquinoline alkaloid, and other substances such as coptisine, epiberberlin, ferulic acid, magnoflorine, palmatine, and worenine. Berberine reportedly has excellent antibacterial, anti-inflammatory, haemostatic, hypotensive, and anticancer activities and has been used to inhibit the central nervous system activity to treat nephritis and induce bronchial smooth muscle expansion (Tang et al. 2016; Lee et al. 2003). Previous studies of the anti-inflammatory effects of $C$. chinensis extracts showed inhibition of lipopolysaccharide (LPS)-induced inducible nitric oxide synthase (iNOS), cyclooxygenase (COX)-2, and tumor necrosis factor (TNF)- $\alpha$ production in peritoneal macrophages, inhibition of apoptosis in pancreatic cells, TNF- $\alpha$ production in keratinocytes, and improvements in memory disorders (Kim et al. 2007; Enk et al. 2007; Wang et al. 2005). In the present study, the signalling mechanisms of the $C$. chinensis extracts were investigated to confirm skin-whitening effects.

\section{Materials and methods}

\section{Cell line and culture}

B16F10 cells were supplied by the Department of Dermatology of the College of Medicine at Seoul National University (Korea). Cells were subcultured in Dulbecco's modified Eagle's medium (DMEM; Welgene Inc., Korea) containing $10 \%$ fetal bovine serum (FBS) $(v / v), 1 \mathrm{mM}$ glutamine, 100 units $/ \mathrm{mL}$ penicillin, and $50 \mu \mathrm{g} / \mathrm{mL}$ streptomycin in $100-\mathrm{mm}$ cell culture dishes in a $37{ }^{\circ} \mathrm{C}$ incubator containing $5 \% \mathrm{CO}_{2}$.

\section{Extraction of $C$. chinensis}

C. chinensis (100 g) plant samples were sonicated for $2 \mathrm{~h}$ in round flasks containing $1 \mathrm{~L}$ of $70 \%$ ethanol. The resulting extracts were decompressed and concentrated using a rotary evaporator (Eyela, Japan) and then dried using a freezing dryer for use in experiments.

\section{Cytotoxicity}

Cell growth inhibitory effects of $C$. chinensis extracts were determined using 3-(4,5-dimethylthiazol-2-yl)-2,5-diphenyltetrazolium bromide (MTT; Sigma-Aldrich, USA) assays. In these experiments, cells were seeded into 96 wells at $2 \times 10^{3}$ cells/well and then cultured for $24 \mathrm{~h}$ at $37^{\circ} \mathrm{C}$ in an incubator containing $5 \% \mathrm{CO}_{2}$. Cells were then cultured with $0-120 \mu \mathrm{g} / \mathrm{mL}$ C. chinensis extracts for $24 \mathrm{~h}$. Following treatments, cells were cultured with MTT for $4 \mathrm{~h}$ to allow formation of formazan crystals. The culture medium was then removed, the formazan crystals were dissolved by adding dimethyl sulphoxide (DMSO; Biopure, Canada), and cell survival rates were determined by measuring absorbance at $540 \mathrm{~nm}$ using a Microplate Reader (Bio-Rad, USA).

\section{Assays of melanin contents}

B16F10 cells were seeded into six-well plates at $5 \times 10^{4}$ cells/well and then cultured for $24 \mathrm{~h}$ at $37{ }^{\circ} \mathrm{C}$ in $5 \% \mathrm{CO}_{2}$. Cells were then treated with $200 \mathrm{nM} \alpha-\mathrm{MSH}$ (Sigma-Aldrich) for $48 \mathrm{~h}$ to induce melanogenesis. Subsequently, numbers of harvested cells were counted, and absorption was measured at $400 \mathrm{~nm}$ after lysing cells with $1 \mathrm{~N}$ $\mathrm{NaOH}$.

\section{qRT-PCR analysis}

To determine changes in the expression of $\alpha-\mathrm{MSH}$ mRNA following treatments with $C$. chinensis extracts, B16F10 cells were cultured in six-well plates at $5 \times 10^{4}$ cells/well. The cells were then treated with $200 \mathrm{nM} \alpha-$ $\mathrm{MSH}$ for $48 \mathrm{~h}$ to induce melanogenesis. The cells were then harvested, and extracted RNA was used to synthesize cDNA using Moloney murine leukaemia virus (M-MLV) reverse transcriptase (Enzynomics, Korea) at $37{ }^{\circ} \mathrm{C}$ for $1 \mathrm{~h}$. Quantitative real-time PCR (qRT-PCR) was then performed using CDNA as a template, and gene expression levels in C. chinensis-treated cells were compared with those in untreated controls. Reaction mixes contained HOT FIREPol EvaGreen PCR Mix Plus (Solis BioDyne, Estonia), 1 pmol of forward primer and reverse primers (Table 1) and $10 \mathrm{ng}$ of cDNA, and qRT-PCR was performed using a LineGene $\mathrm{K}$ (BioER, China) instrument with initial denaturation at $94{ }^{\circ} \mathrm{C}$ for $3 \mathrm{~min}$, followed by 40 cycles of denaturation $\left(94^{\circ} \mathrm{C}, 30 \mathrm{~s}\right)$, annealing $\left(58{ }^{\circ} \mathrm{C}, 30 \mathrm{~s}\right)$, and polymerization $\left(72{ }^{\circ} \mathrm{C}, 30 \mathrm{~s}\right)$. 
Table 1 Primers used in the qRT-PCR analyses

\begin{tabular}{lll}
\hline Gene & Forward primer $\left(5^{\prime} \rightarrow 3^{\prime}\right)$ & Reverse primer $\left(5^{\prime} \rightarrow 3^{\prime}\right)$ \\
\hline MITF & GGAACAGCAACGAGCTAAGG & TGATGATCCGATTCACCAGA \\
Tyrosinase & CAAGTACAGGGATCGGCCAAC & GGTGCATTGGCTTCTGGGTAA \\
$\beta$-actin & CCCTGTATGCCTCTGGTC & GTCTITACGGATGTCAACG \\
\hline
\end{tabular}

PCRs were validated using melting curves, and gene expression levels were normalized to that of $\beta$-actin. The expression of miR-340 was determined using PCR according to the instructions of the miScript SYBR ${ }^{\circ}$ Green PCR Kit (Qiagen, Germany) and a LineGene K instrument (BioER). Expression levels were normalized to that of U6 miRNA.

\section{miRNA transfection}

To determine whether miR-340 regulates MITF expression in B16F10 cells following treatment with $C$. chinensis extracts, we transformed cells with anti-miR-340 (Bioneer, Korea) using RNAi max (Invitrogen, USA) and negative scramble miRNA as a control.

\section{Western blotting analysis}

B16F10 cells were seeded into six-well plates at $5 \times 10^{4}$ cells/well and then cultured for $24 \mathrm{~h}$. Subsequently, the cells were treated with $C$. chinensis extracts and $200 \mathrm{nM}$ $\alpha-\mathrm{MSH}$ and then cultured for an additional $48 \mathrm{~h}$. The cells were lysed and centrifuged in radioimmunoprecipitation assay (RIPA) buffer, and supernatants were subjected to sodium dodecyl sulphate-polyacrylamide gel electrophoresis on $10 \%$ gels. Proteins were then transferred to nitrocellulose membranes (Bio-Rad), blocked for $1 \mathrm{~h}$ in Tris-buffered saline/Tween 20 (TBS/T) buffer containing 5\% skimmed milk and incubated with primary monoclonal antibodies against MITF, tyrosinase, and $\beta$-actin. Protein bands were detected using appropriate secondary antibody Immobilon Western Chemiluminescent HRP substrate (Thermo Scientific, USA), and images were developed using ChemiDoc (Bio-Rad).

\section{Luciferase assays}

B16F10 cells were transfected with reporter plasmid (pGL3-MITF-3'UTR, $1 \mu \mathrm{g}$ ) and normalization plasmid (pCMV- $\beta$-gal, $0.2 \mu \mathrm{g}$ ) using Lipofectamine 2000 (Invitrogen). The cells were cultured for $24 \mathrm{~h}$ under appropriate conditions and then treated with reagents for $24 \mathrm{~h}$. The cells were then harvested in $100 \mu \mathrm{L}$ of $\times 1$ luciferase lysis buffer (Promega, USA) at $4{ }^{\circ} \mathrm{C}$ for $10 \mathrm{~min}$ and then centrifuged at $12,000 \mathrm{rpm}$ for $10 \mathrm{~min}$. Luciferase assays were then performed in the resulting supernatants using luciferase reagent (Promega) and a Luminometer (Veritas, USA). Luciferase activities were normalized to $\beta$-galactosidase, as determined using O-nitrophenyl- $\beta$-D-galactopyranoside assays.

\section{Statistical analysis}

All experiments were independently performed in triplicate. Data are expressed as means \pm standard deviations. Statistical analyses were performed using Microsoft Excel, and differences were considered significant when $p<0.05$.

\section{Results}

\section{Regulation of melanogenesis by $C$. chinensis extracts}

Cytotoxic activities of $C$. chinensis extracts in mouse melanoma cells were determined using MTT assays, and effective concentration ranges were calculated. B16F10 melanoma cell survival rates were $90 \%$ or higher in the presence of up to $15 \mu \mathrm{g} / \mathrm{mL} \quad C$. chinensis extracts (Fig. 1a). Melanin contents in the mouse melanoma cells were then measured to assess skin-whitening effects of C. chinensis extracts. Under these conditions, $\alpha-\mathrm{MSH}-$ mediated melanogenesis was inhibited by treatments with $C$. chinensis extracts (Fig. 1b).

C. chinensis extracts also inhibited tyrosinase activities by more than $50 \%$ at $15 \mu \mathrm{g} / \mathrm{mL}$ (Fig. 2a), which was related to concomitant decreases in tyrosinase expression (Fig. 2b, d). In subsequent qRT-PCR and Western blotting analyses, decreases in melanogenesis were a

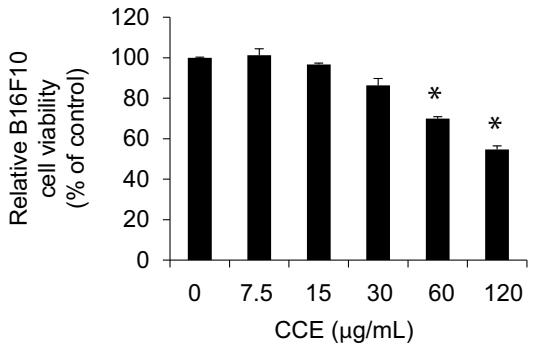

b

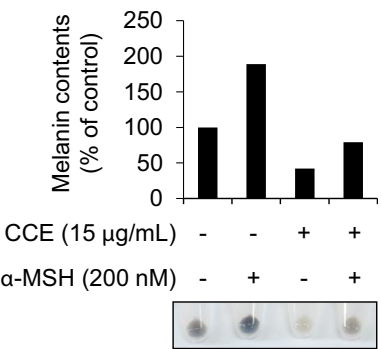

Fig. 1 C. chinensis extracts decreased a-MSH-mediated melanogenesis in B16F10 cells. a Cytotoxicity of C. chinensis extracts. b Melanin contents in C. chinensis-treated B16F10 mouse melanoma cells. Statistically significant differences are indicated with an asterisk for $p<0.05$ 

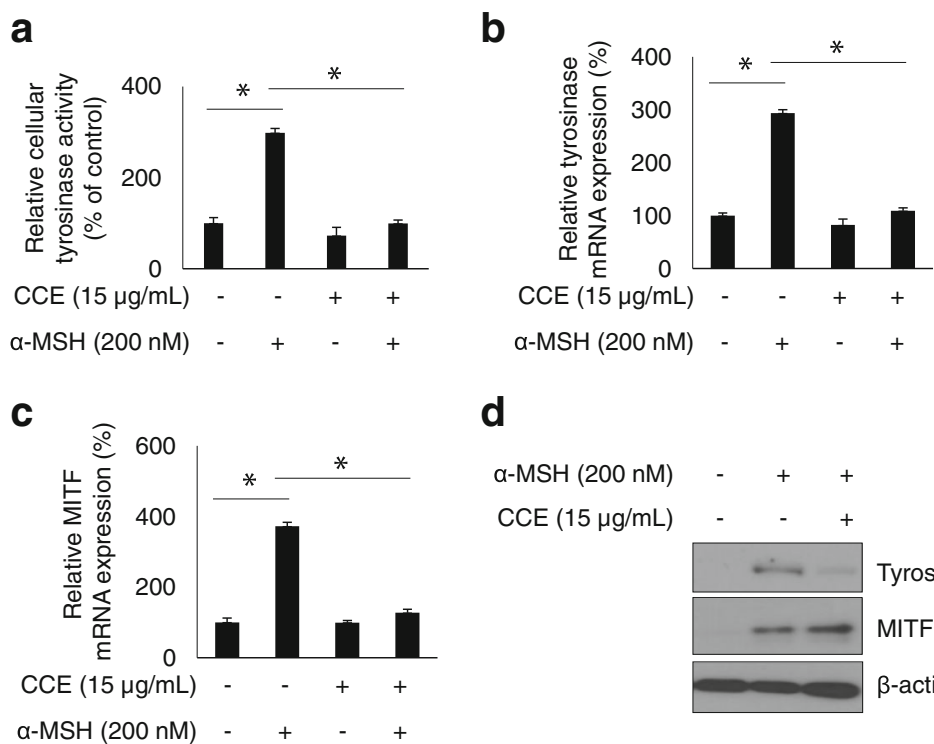

\section{d}

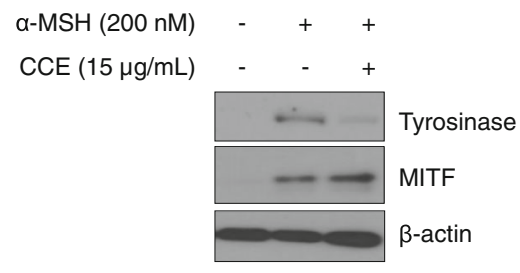

Fig. 2 C. chinensis extracts decrease the expression and activity of melanogenesis-related genes. a C. chinensis-mediated changes in tyrosinase activity. b Tyrosinase mRNA expression. c MITF mRNA expression. d Melanogenesis-related protein expression. Statistically significant differences are indicated with an asterisk for $p<0.05$

correlated with tyrosinase mRNA and protein expression levels and with MITF protein expression (Fig. 2c, d).

\section{Regulation of miR-340 expression by C. chinensis extracts} Previous studies showed that MITF translation is regulated by miR-340. Accordingly, treatments of the present B16F10 melanoma cells with $C$. chinensis extracts at 0, 7.5 , and $15 \mu \mathrm{g} / \mathrm{mL}$ increased miR-340 expression in a concentration-dependent manner (Fig. 3).

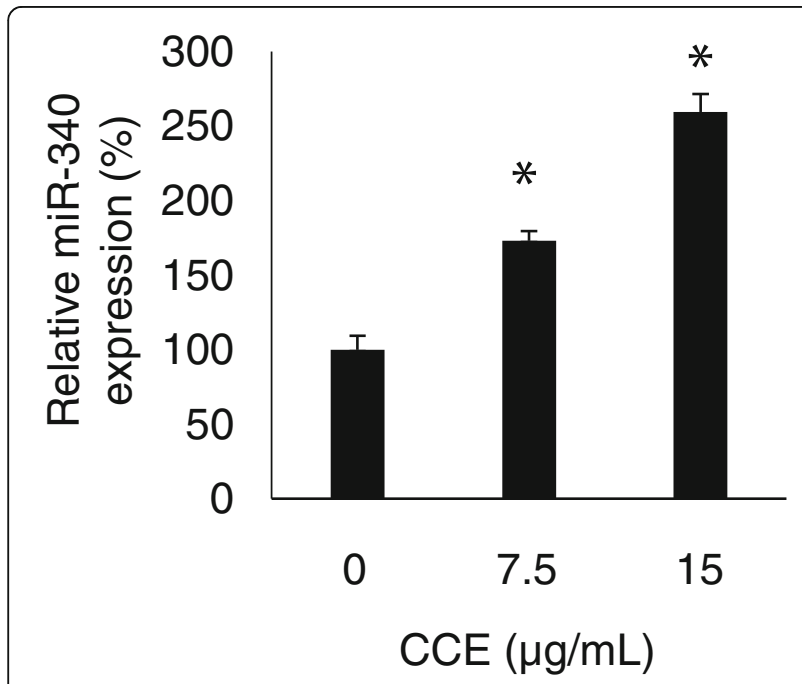

Fig. 3 Regulation of miR-340 expression by C. chinensis extracts. C. chinensis extracts increased miR-340 expression in a concentration-dependent manner. Statistically significant differences are indicated with an asterisk for $p<0.05$
Regulation of MITF by C. chinensis extracts is mediated by miR-340

To confirm the roles of the miR-340-MITF axis in the regulation of melanogenesis by $C$. chinensis extracts, we performed reporter assays of the miR-340 target on the MITF promoter. In these experiments (Fig. 4), luciferase activity was decreased following treatments with $C$. chinensis extracts but was recovered following transfection with antimiR-340.

\section{Discussion}

During melanogenesis, melanin is produced from L-tyrosine by the key enzyme tyrosinase (Pillaiyar et al. 2017; Kwon et al. 2014; D’Mello et al. 2016), and various skin-whitening raw materials have been developed to inhibit the expression and activity of tyrosinases (Gunia-Krzyżak et al. 2016; Lee et al. 2016; Choi et al. 1998). The present study shows that C. chinensis extracts inhibit melanogenesis by decreasing tyrosinase activity (Fig. 2a) and expression (Fig. 2b, d). Moreover, we investigated the roles of $\alpha-\mathrm{MSH}$ and MITF in tyrosinasemediated melanogenesis and showed that MITF protein but not mRNA expression was decreased in the presence of C. chinensis, suggesting regulation by posttranscriptional mechanisms. Among potential regulators, miRNAs of 16 to 29 nucleotides are known to regulate protein expression by inhibiting translation (Bartel 2004; Murchison and Hannon 2004). Previous studies showed that miR-340 regulates melanogenesis by directly inhibiting MITF (Goswami et al. 2015). In agreement, miR-340 expression was increased and luciferase activity of the 

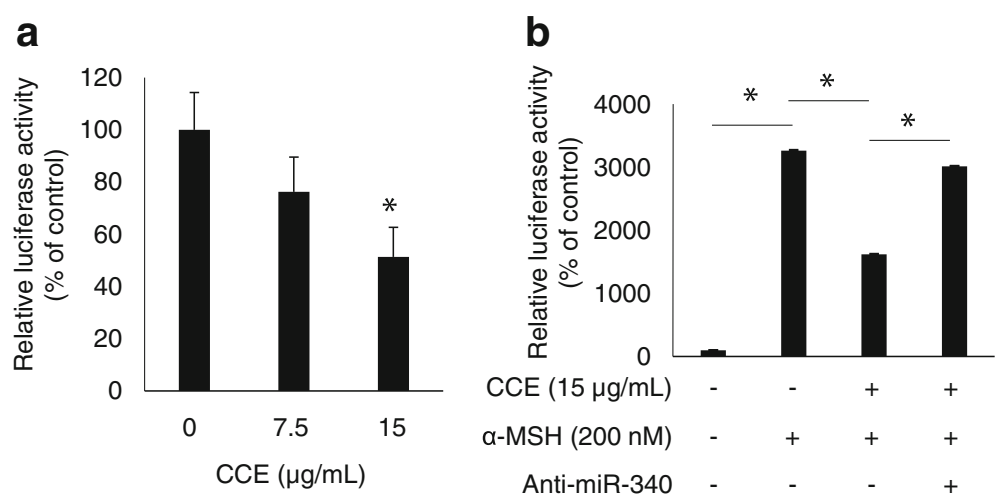

Fig. 4 C. chinensis extracts regulated melanogenesis via the miR-340-MITF axis. a C. chinensis-mediated changes in luciferase activity of the miR-340 target sequence. $\mathbf{b}$ miR-340-mediated blockade of $C$. chinensis-induced luciferase activity of the miR-340 target sequence. Statistically significant differences are indicated with an asterisk for $p<0.05$

MITF reporter sequence was decreased following the present treatments with C. chinensis extracts (Fig. 4). Moreover, transfection with anti-miR-340 restored MITF protein levels under these conditions, confirming that miR-340 inhibits translation of MITF in the presence of $C$. chinensis extracts. Taken together, the present data show that $C$. chinensis extracts inhibit MITF translation by increasing miR-340 expression, leading to decreased tyrosinase protein and mRNA expression and reduced melanogenesis.

\section{Conclusions}

To investigate the potential of $C$. chinensis extracts as a raw material for skin-whitening cosmetics, we initially determined changes in tyrosinase activities in B16F10 melanoma cells and showed that C. chinensis extracts inhibit melanogenesis in a concentrationdependent manner. Subsequent Western blotting experiments showed that tyrosinase and MITF protein expression levels were decreased by $C$. chinensis extracts, whereas only tyrosinase mRNA levels were affected under these conditions, indicating that MITF is regulated at the protein level. Accordingly, the known MITF translation regulator miR-340 was induced following treatments with $C$. chinensis extracts, and the resulting suppression of MITF was mitigated by an anti-miR-340 antibody. The results of the present study confirm the skin-whitening effects of $C$. chinensis extracts and demonstrate that miR-340mediated inhibition of MITF translation leads to decreased tyrosinase expression and melanin synthesis.

\section{Abbreviations}

C. chinensis: Coptis chinensis; CAMP/PKA: Cyclic monophosphate/protein kinase A; CCE: C. chinensis extracts; COX: Cyclooxygenase; CREB1: CAMP-responsive element-binding protein 1; DMEM: Dulbecco's modified Eagle's medium; DMSO: Dimethyl sulphoxide; FBS: Fetal bovine serum; iNOS: Inducible nitric oxide synthase; LPS: Lipopolysaccharide; MC1R: Melanocortin-1 receptor; MITF: Microphthalmia-associated transcription factor; M-MLV: Moloney murine leukaemia virus; MTT: 3-(4,5-Dimethylthiazol-2-yl)-2,5-diphenyltetrazolium bromide; POMC: Proopiomelanocortin; GRT-PCR: Quantitative real-time PCR; RIPA: Radioimmunoprecipitation assay; TBS/T: Tris-buffered saline/Tween 20; TNF: Tumor necrosis factor; TRP: Tyrosinase-related protein; a-MSH: aMelanocyte-stimulating hormone

\section{Acknowledgements}

This work was supported by a grant from the Korean Health Technology R\&D Project (Grant No. HN13C0075), Ministry of Health \& Welfare, Republic of Korea.

\section{Funding}

This work was supported by a grant from the Korean Health Technology R\&D Project (Grant No. HN13C0075), Ministry of Health \& Welfare, Republic of Korea.

Availability of data and materials Not applicable

\section{Authors' contributions}

HKL, SJ, SHS, DJ, SJC, and KK performed the experiments. KYK, JEK, SHJ, and $\mathrm{HJC}$ were involved in experimental design and advising. HKL, ISA, and HJC analysed the data and wrote the manuscript. All authors have read and approved the final manuscript.

Ethics approval and consent to participate Not applicable

Consent for publication

Not applicable

\section{Competing interests}

The authors declare that they have no competing interests.

\section{Publisher's Note}

Springer Nature remains neutral with regard to jurisdictional claims in published maps and institutional affiliations.

\section{Author details}

${ }^{1}$ Korea Institute of Dermatological Sciences, Cheongju-si, Chungcheongbuk-do 28160, Republic of Korea. ${ }^{2}$ URG Inc., URG Building, Seochogu, Seoul 06753, Republic of Korea. ${ }^{3}$ Department of Cosmetology, Kyung-In Women's University, Incheon 21014, Republic of Korea.

${ }^{4}$ Department of Beauty Art, Faculty of Art, Suwon Women's University, Suwon-si, Gyeonggi-do 16632, Republic of Korea. ${ }^{5}$ Department of Skin Care and Beauty, Osan University, Osan-si, Gyeonggi-do 18119, Republic of Korea. ${ }^{6}$ Department of Skin Care and Cosmetics, Osan University, Osan-si45

Cheonghak-roGyeonggi-do 18119, Republic of Korea. 
Received: 19 May 2017 Accepted: 20 September 2017

Published online: 23 October 2017

\section{References}

Amaro-Ortiz A, Yan B, D'Orazio JA. Ultraviolet radiation, aging and the skin: prevention of damage by topical CAMP manipulation. Molecules. 2014;19:6202-19.

Bartel DP. MicroRNAs: genomics, biogenesis, mechanism, and function. Cell. 2004;116:281-97.

Boissy RE, Sakai C, Zhao H, Kobayashi T, Hearing VJ. Human tyrosinase related protein-1 (TRP-1) does not function as a DHICA oxidase activity in contrast to murine TRP-1. Exp Dermatol. 1998;7:198-204.

Buscà R, Ballotti R. Cyclic AMP a key messenger in the regulation of skin pigmentation. Pigment Cell Res. 2000;13:60-9.

Chakraborty AK, Funasaka Y, Slominski A, Ermak G, Hwang J, Pawelek JM, et al. Production and release of proopiomelanocortin (POMC) derived peptides by human melanocytes and keratinocytes in culture: regulation by ultraviolet B. Biochim Biophys Acta. 1996;1313:130-8.

Choi BW, Lee BH, Kang KJ, Lee ES, Lee NH. Screening of the tyrosinase inhibitors from marine algae and medicinal plants. Kor J Pharmacogn. 1998;29:237-42.

D'Mello SA, Finlay GJ, Baguley BC, Askarian-Amiri ME. Signaling pathways in melanogenesis. Int J Mol Sci. 2016;17:1144.

Enk R, Ehehalt R, Graham JE, Bierhaus A, Remppis A, Greten HJ. Differential effect of Rhizoma coptidis and its main alkaloid compound berberine on TNF-a induced NFkB translocation in human keratinocytes. J Ethnopharmacol. 2007;109:170-5.

Fajuyigbe D, Young AR. The impact of skin colour on human photobiological responses. Pigment Cell Melanoma Res. 2016;29:607-18.

Fitzpatrick TB, Miyamoto M, Ishikawa K. The evolution of concepts of melanin biology. Arch Dermatol. 1967;96:305-23.

Goswami S, Tarapore RS, Poenitzsch Strong AM, TeSlaa JJ, Grinblat Y, Setaluri V, et al. MicroRNA-340-mediated degradation of microphthalmia-associated transcription factor (MITF) mRNA is inhibited by coding region determinantbinding protein (CRD-BP). J Biol Chem. 2015;290:384-95.

Gunia-Krzyżak A, Popiol J, Marona H. Melanogenesis inhibitors: strategies for searching for and evaluation of active compounds. Curr Med Chem. 2016:23:3548-74

Kim EK, Kwon KB, Han MJ, Song MY, Lee JH, Lv N, et al. Coptis chinensis extract protects against cytokine-induced death of pancreatic $\beta$-cells through suppression of NF-KB activation. Exp Mol Med. 2007;39:149-59.

Kwon KJ, Bae S, Kim K, An IS, Ahn KJ, An S, Cha HJ. Asiaticoside, a component of Centella asiatica, inhibits melanogenesis in B16F10 mouse melanoma. Mol Med Rep. 2014;10:503-7.

Lee DU, Kang YJ, Park MK, Lee YS, Seo HG, Kim TS, et al. Effects of 13-alkyl-substituted berberine alkaloids on the expression of COX-II, TNF-alpha, iNOS and IL-12 production in LPS-stimulated macrophages. Life Science. 2003;73:1401-12.

Lee SY, Baek N, Nam TG. Natural, semisynthetic and synthetic tyrosinase inhibitors. J Enzyme Inhib Med Chem. 2016;31:1-13.

Murchison EP, Hannon GJ. miRNAs on the move: miRNA biogenesis and the RNAi machinery. Curr Opin Cell Biol. 2004;16:223-9.

Nasti TH, Timares L. MC1R, eumelanin and pheomelanin: their role in determining the susceptibility to skin cancer. Photochem Photobiol. 2015;91:188-200.

Pillaiyar T, Manickam M, Namasivayam V. Skin whitening agents: medicinal chemistry perspective of tyrosinase inhibitors. J Enzyme Inhib Med Chem. 2017;32:403-25

Saha B, Singh SK, Sarkar C, Bera R, Ratha J, Tobin DJ, Bhadra R. Activation of the Mitf promoter by lipid-stimulated activation of p38-stress signalling to CREB. Pigment Cell Res. 2006;19:595-605.

Tang C, Wu XD, Yu YM, Duan H, Zhou J, Xu L. Cell extraction combined with offline HPLC for screening active compounds from Coptis chinensis. Biomed Chromatogr. 2016;30:658-62.

Tsukamoto K, Jackson IJ, Urabe K, Montague PM, Hearing VJ. A second tyrosinase-related protein, TRP-2, is a melanogenic enzyme termed DOPAchrome tautomerase. EMBO J. 1992;11:519-26.

Videira IF, Moura DF, Magina S. Mechanisms regulating melanogenesis. An Bras Dermatol. 2013;88:76-83.

Wang X, Xing D, Wang W, Su H, Tao J, Du L. Pharmacokinetics of berberine in rat thalamus after intravenous administration of Coptidis rhizoma extract. Am J Chin Med. 2005;33:935-43.

\section{Submit your next manuscript to BioMed Central and we will help you at every step:}

- We accept pre-submission inquiries

- Our selector tool helps you to find the most relevant journal

- We provide round the clock customer support

- Convenient online submission

- Thorough peer review

- Inclusion in PubMed and all major indexing services

- Maximum visibility for your research

Submit your manuscript at www.biomedcentral.com/submit
Biomed Central 